\title{
Study on Aesthetic Characteristics of Tin Embroidery Costume in Qiandongnan Prefecture
}

\author{
Ren Shan \\ Faculty of Humanities and Arts, Macau University of Science and Technology \\ Macau, China \\ College of Design, Beijing Normal University Zhuhai \\ Zhuhai, Guangdong, China \\ renshan0211@126.com
}

\begin{abstract}
Tin embroidery costume of Jianhe Miao in Qiandongnan prefecture has profound aesthetic implication and exploration value. Tin embroidery in jianhe is the one and only embroidery method in the whole world. This embroidery method only exists in a few number of Miao villages. Miao people in Jianhe all follow the old traditional techniques in the process of planting, spinning, weaving and dyeing. Based on the field research, taking Jianhe Mindong as an example, this paper analyzes the aesthetic characteristics of tin embroidery costume from its color, pattern and manufacturing process to seek the underlying connotation of national culture.
\end{abstract}

Keywords-Miao Nationality; Tin embroidery; Costume; Aesthetics

\section{INTRODUCTION}

Jianhe County in southeast Guizhou province keeps a unique craftsmanship that has been handed down for over five to six hundred years-the tin embroidery technique. Metallic threads are embroidered onto navy blue cloth, highlighting a sharp contrast between colors.

History is what the Miao ethnic people wear. With no written script, the Miao have long used textile making as their method of language to record their history and beliefs. Their techniques are an instrument of vocabulary. Impressively, in embroidery, the breath of intricate and stunning surface embellishments is achieved with them most simple of tools-a needle and thread.

Costume is the carrier of Miao culture, in which Miao embroidery occupies an important position. As embroidery is one of the spiritual pillars of the Miao people, they are even willing to spend four to five years to make a dress. The ancestors of Miao had the extreme pursuit of embroidery technology, which made Miao embroidery have the characteristics that other nationalities cannot copy no matter in technology, content or connotation [1].

For thousands of years, the life of the Miao people has paid great attention to the art of embroidery, which has been widely used in daily life. For example, the costumes of different ages and different genders are all exquisite works of art. The embroidery art reflects the Miao people's yearning for life and pursuit of happiness, and records the glorious course of them. It is a flower in the treasure house of Miao history and culture. In the long process of development, Miao embroidery has formed a sophisticated combination of mature and exquisite techniques and materials to achieve a more pleasing effect. Some techniques are very unique, such as broken thread embroidery, crepe embroidery, and tin embroidery, which are never seen in other ethnic groups. Although some techniques have already disappeared, most of handicrafts have been preserved.

There has never been a unified statement to Miao embroidery species. To be sure, there are at least 20 kinds. Inside the 20 kinds of embroidery, tin embroidery is awfully special. Miao people use metal "tin" as the materials to finish a piece of embroidery. Because of the particularity of materials, it is more special than other materials that use natural silk thread as embroidery materials, in the way that changes people's traditional concept of materials for embroidery. Therefore, Miao tin embroidery has a special status and technological value in the ethnic groups and even around world.

Because of the special materials and the complicated making process, Miao tin-embroidered costumes are unique in China's embroidery and were listed in the first batch of intangible cultural heritage list in 2006. Miao tin embroidery is developed and extended on the basis of weaving and cross-stitch As one of the most unique costumes, compared with other Miao costumes, tin embroidery costume has a strong visual impact and contains high artistic value [2].

\section{OVERVIEW OF JIANHE MIAO TIN EMBROIDERY COSTUMES}

Miao have no written language, people remember things by word of mouth and ears, and the ethnic culture is precipitated in the exquisite and gorgeous national costumes. The basic characteristic of Miao costume is that men's wears are simple and women's wears are gorgeous. Pleated skirt is the basic element in Miao's costumes that matches different tops to form different sub-lines style of Miao costumes.

Miao tin embroidery costumes are distributed in a very concentrated area, which is located in the middle reaches of Qingshui River. All of them are in Jianhe, southeast of Qiandongnan, mainly in Nanzhai town, Mindong town and Nanjia town. Those towns are lack of development where restricts tin embroidery to some extent. As the number of women working outside the area increases year by year, the number of subjects of embroidery creation increases year by year reduced. 
Now young women are going out to work. Most of those who stay at home are older women. With the change of the concept of people's lives, people in tin embroidered costume on the decrease. Some young women in villages are reluctant to wear tin-embroidered clothes at ordinary times. Even during the important festivals, few people wear tin-embroidered clothes. In addition to the skills inheritance crisis, designs the cultural significance has gradually forgotten and lost, young people are not willing to understand the meaning of cultural content and design [3].

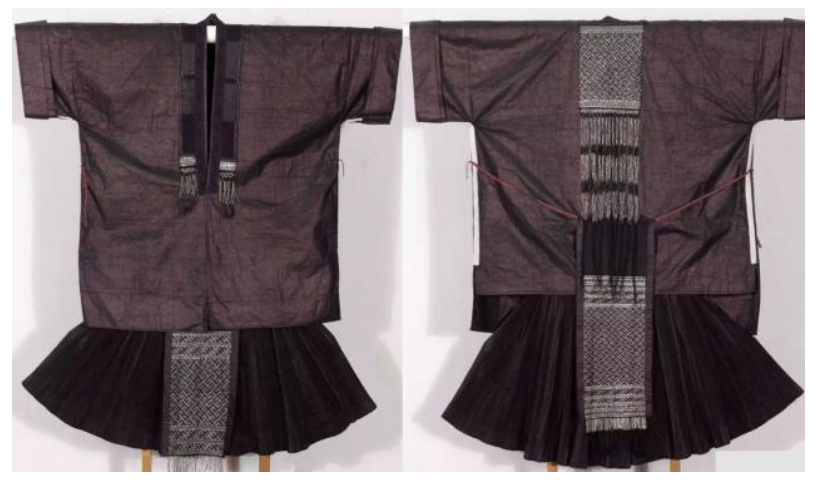

Fig. 1 The Plan of Tin Embroidery Costume

There are 11 kinds of costumes of Jianhe Miao, which respectively are Jiuyang style, Neizhai style, Gaoqiu style, Jiugan style, Gaoyong style, Liuli style, Baidao style, Fangwu style, Nanmeng style, Gaopang style and Wumen style. Tin embroidery costume belongs to Gaoqiu style; the basic shape of Gaoqiu style is front opening top with pleated skirt and the waist. The upper sleeves are short and wide, just over the elbow. The skirt length belongs to the middle skirt system, and the length is below the knee above the calf. The legs are wrapped in striped cloth and the top is fixed with a blue-purple ribbon. Wear blue socks and embroidered shoes, with the front of the hosiery opening two centimeters, and nail double row of fabric button. The fabrics of tin embroidery costumes are selfwoven cotton cloth, through weaving and dyeing and finishing to brown purple bright cloth. Tin embroidery is not only used tin pieces to embroider, the bottom of the fabrics are covered by line embroidery [4]. Line embroidery uses the method of cross-stitch work. The decorative pattern of the neckline and the main body of the front does not need to be affixed with tin pieces, and the decorative craft of tin pieces is mainly concentrated on the end of the front, the back of the coat and the front and back of the pleated skirt, forming various patterns, and the effect is extremely shocking.

\section{COLOR FEATURES OF TIN EMBROIDERY COSTUMES}

Color is an important part of Miao costume. Miao people are good at expressing the beauty of their costume with various strong and gorgeous colors. The colors of tin embroidery are more simple than those produced by other Miao embroidery techniques. The main color of the tin embroidery dress is the silver-white tin embroidery pieces of the front and back of the waist with the bright brown and purple cloth, forming a strong color contrast effect.
The changes and application of colors are mainly reflected on the part of cross-stitch work, which appear at the front of the costume, the back end of the collar, the back end of the apron and the bottom of the apron. Red, purple, blue, green, black and brown are mostly used in the tin embroidery costumes. Through the combination of these colors, the tin embroidery costumes can achieve different visual effects. Main colorific collocation method has adjacent colorific collocation, contrast colorific collocation and complementary colorific collocation, there will be more than one collocation method in the same embroider. Adjacent color collocation, common color combination is red and purple, blue and purple, blue and green, etc. Contrast color matching, common color combination is red blue, green and purple, etc. Complementary color collocation, common color combination is red green, yellow purple, etc. The bright and dark color is related to the age of the wearer. Young people prefer bright colors, while old people prefer dark colors. The color collocation of tin embroidery costumes is very artistic, which is both strong and harmonious, and reflects the unique aesthetic taste of Miao people in Jianhe [5].

\section{PATTERn FEATURES OF TIN EMBROIDERY COSTUMES}

In the past, girls used to learn tin embroidery at an early age as it could be found on any daily wearing. It was also believed to show a girl's virtue and capability. By the time of their wedding, mother would give her a set of embroidery patterns handed down for generations. Nowadays, more and more women choose to leave their hometown and find jobs in big cities. Fewer and fewer people still wear clothes with tin embroidery and even fewer young people who are willing to learn the skill. Many traditional patterns have lost their connotations to the younger generation [6].

\section{A. Implication of the Patterns}

For the ethnic groups without own written language, the costume is their unwritten book. These "myths" worn on people's bodies, after thousands of years of mysterious inheritance, infiltrate the original heart and image of national collective consciousness, and are symbolic art works after the formalization of traditional ethnic culture. The history, customs, religious beliefs and moral norms of the ethnic groups are all recorded in the patterns.

Taking Jianhe Mindong as an example, through field investigation, it is found that there are mainly three types of tin embroidery patterns used in this area, which are called floating flowers, four-strokes flowers and wangzi flowers. Floating is a kind of phytoplankton which is very common in the field. Because its shape is similar to floatation, it is called floating flowers. Swastika has a long history of inheritance and has different interpretations in different countries and regions. The swastikas are called Wanshou flowers, representing healthy, longevity and happiness. Wan xue, one of the interviewees of Jianhe Mindong, said that mainly based on the embroidery order, this pattern was called four-strokes flowers in the Mindong area. With the center of the design as the starting point, up and down, left and right, each side has one line, totally four lines, so is called four-strokes flowers. As the name implies, the wangzi pattern is similar to the Chinese character "wang". 
The custom of Miao called wang zi heaven and earth, and it can also be interpreted as people who understand heaven and earth. Therefore, wang zi also has the meaning of leader. Although different regions have different names for the same patterns, they all have one thing in common, which is related to primitive myths, religious beliefs and totem worship. This is a symbolic projection of ethnic culture and social psychology. The patterns are condensed into a cultural code, which is passed down and recorded along with the costume.

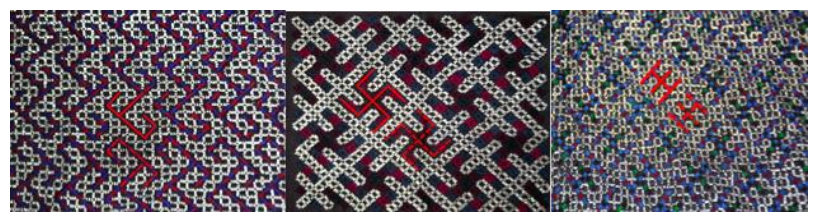

Fig. 2 Three Kinds of Tin Embroidery Pattern

\section{B. Composition of the Patterns}

The patterns of tin embroidery costumes are different from those of butterfly, bird, ox, chicken, dragon and fish, which are commonly seen in traditional Miao embroidery. It is less variable and the pattern is fixed. The front hem of the pleated skirt is not decorated with color shading, and the pattern is slightly larger. The pleated skirt backswing and back lay are decorated with color shading, and the patterns are small and dense.

Geometry patterns have two characteristics: symmetry and continuity. Tin embroidery patterns follow the formal beauty law, composition neat, stress symmetry and continuity, according to a certain rule of repeated combination arrangement. The patterns are arranged in a 180-degree symmetry. The adjacent patterns are arranged in a 90-degree vertical arrangement. Regular changes have formed rhythm, with a sense of modernity and design.

\section{TECHNOLOGICAL FEATURES OF TIN EMBROIDERY COSTUMES}

The making process of tin embroidery costumes is completed by hand from the initial planting of cotton, stretch fabric, weaving, stitching, dyeing, and finally embedding tin strips.

Tin embroidery is usually found in three parts of the clothes, they are front skirt, back skirt and vest. Each part is handmade and homemade, involving several procedures, spinning, weaving, dying, sketching, sewing and tin stitching. The technique is very time consuming. It often takes two to three hours to stitch a fine zigzag pattern on a white cotton cloth and wrapping fine metal strips over and under each stitch. Each step along the way requires fine skills. Therefore, it usually takes more than five years to finish a set of tin embroidery costume.

Miao people uphold silver, and it is a very important property for them. These exquisite silver ornaments reflect Miao people's aesthetic taste and are also important symbols of their rank and status. But silver is quite expensive, in order to achieve the effect of decoration, tin embroidery to replace silver with tin pieces. Silver and tin are different in approach but equally satisfactory in result. With the further development of commercialization, they use antimony to replace tin, which is cheaper. In Jianhe, we found that many villagers sell tinembroidered costumes or embroidery pieces as their main way of making a living. So to cut costs, they chose to make clothes out of antimony. But compared antimony pieces with tin pieces, tin bars are harder and brighter [7].

The whole tin embroidery process has more than ten processes; all of the process is handmade. The project was extremely complex. A piece of clothing on the top of an infinite number of tin knot made of silver glitter of beautiful, concise, simple elegant patterns. All the people who see it all marvel and love. Miao language calls the tin bar "nansai". Tin embroidery is a kind of embroidery that cut about $1.2 \mathrm{~mm}$ wide tin strips wrapped in the bottom of the yarn. To finish a piece of tin embroidery, people should do screening, penetration, fastening, cutting and other processes. To concentrate the eye and reduce wear and tear, a woman will prepare a piece of cloth about 20 centimeters square before embroidering, and cut out a round hole about 1.5 centimeters in diameter in the middle, so as to aim at the part to pick up the tin bar, the embroidery edge will move until it is finished. Main tools of tin embroidery are right needle, tin bars, and scissors. First, $1 \mathrm{~mm}$ tin strips are cut along the edge of tin sheet with scissors. The left hand holds the tin strip, and the right hand holds the needle. Such a minimum unit of the tin bar is completed, the process repeated until the completion of the whole embroidery. It can be seen that the craft of tin embroidery is very complicated.

\section{CONCLUSION}

The ethnic art takes the theme, pattern and color as the allegorical symbol of the connotation of a particular concept in a broad sense, and used the techniques of homophony and symbol to express the ideal and desire to avoid evil spirits, seek good fortune and avoid disaster, yearn for a better life and promote the value of life. When we use tin aesthetic point of view to analyze the Miao tin embroidery art, found that it has abundant content and perfect form, accumulate a wealth of historical and aesthetic implication, embodies the Miao people's feelings and evaluation to the social life, into the knowledge, feeling, meaning, reflects the Miao people's life, love of nature to our national culture.

Clothing is an important representation of human aesthetic pursuit. The aesthetic features of tin embroidery costumes are not only formal, but contain rich connotations, inheriting the history, culture and memory of miao society, full of the simplest feelings of miao people to beauty in jianhe. The colors, patterns and crafts of tin embroidery costumes are the most basic elements to carry their national culture. No matter they are abstract patterns or concrete composition forms, they are always showing the miao people's respect for nature, their love for national culture and their yearning for a better life. 


\section{ACKNOWLEDGMENT}

Quality project of Guangdong province "School-school collaborative international education model and mechanism innovation pilot area" (NO.2014307); Quality project of Beijing Normal University Zhuhai "Specialty training of applied talents in Fashion and Accessories Design" (NO.201540); Project of Beijing Normal University Zhuhai “ Teacher research capacity promotion program"(NO.201850008).

\section{REFERENCES}

[1] DENG Qiyao, The secret language of clothing -- the symbol of Chinese national costume culture, Sichuan people press, p.3, 2005.

[2] LIU Chunyu, ZHEN Yong, Field investigation on the tin embroidery technology and patterns in jianhe, guizhou, Chinese culture BBS, 2016, pp.111-114.

[3] PENG Yong, PAN Shaoxiong, An analysis of the formal beauty features of the embroidery patterns of miao ethnic group in Jianhe, guizhou, art education research, 2014, p. 22.

[4] PENG Yong, A probe into the aesthetics of tin embroidery art of miao nationality, National art, 2012, pp.126-127.

[5] MA Wenjing, Discussion on the inheritance and development of traditional handicrafts in ethnic areas, Guizhou ethnic studies, 2009, pp. 165-168.

[6] LI jiayi, A study on the innovation of tourist crafts with the integration of ethnic cultural elements and modern design concepts, Guizhou ethnic studies, 2015, pp. 166-168.

[7] ZHOU Ying, Analysis on the artistic characteristics of qiandongnan jianhe miao tin embroidery clothing, Sichou, vol.52, pp.64-68, Nov. 2015. 